\title{
Compulsive Internet Use Among Adolescents: Bidirectional Parent-Child Relationships
}

\author{
Regina J. J. M. van den Eijnden • Renske Spijkerman • \\ Ad A. Vermulst • Tony J. van Rooij • \\ Rutger C. M. E. Engels
}

Published online: 2 September 2009

(C) The Author(s) 2009. This article is published with open access at Springerlink.com

\begin{abstract}
Although parents experience growing concerns about their children's excessive internet use, little is known about the role parents can play to prevent their children from developing Compulsive Internet Use (CIU). The present study addresses associations between internetspecific parenting practices and CIU among adolescents, as well as the bidirectionality of these associations. Two studies were conducted: a cross-sectional study using a representative sample of 4,483 Dutch students and a longitudinal study using a self-selected sample of 510 Dutch adolescents. Results suggest that qualitatively good communication regarding internet use is a promising tool for parents to prevent their teenage children from developing CIU. Besides, parental reactions to excessive internet use and parental rules regarding the content of internet use may help prevent CIU. Strict rules about time of internet use, however, may promote compulsive tendencies. Finally, one opposite link was found whereby CIU predicted a decrease in frequency of parental communication regarding internet use.
\end{abstract}

Keywords Internet - Adolescents · Parents .

Compulsive internet use $\cdot$ Internet addiction

R. J. J. M. van den Eijnden $(\bowtie)$

Faculty of Social and Behavioral Sciences, Utrecht University, P.O. Box 80140, 3508 TC Utrecht, The Netherlands

e-mail: r.j.j.m.vandeneijnden@uu.nl

R. J. J. M. van den Eijnden · T. J. van Rooij

Addiction Research Institute,

Rotterdam, The Netherlands

R. Spijkerman · A. A. Vermulst • R. C. M. E. Engels Behavioral Science Institute, Radboud University Nijmegen, Nijmegen, The Netherlands

\section{Introduction}

Using the internet has become one of the most popular leisure-time activities among adolescents in Western societies. In the Netherlands, adolescents aged 11 to 15 use the internet for leisure activities about $11 \mathrm{~h}$ a week on average, ranging from $9 \mathrm{~h}$ per week among 11-year-olds to $15 \mathrm{~h}$ per week among 15-year-olds. Moreover, adolescents aged 14 and older regard internet use as a more important leisuretime activity than watching TV (Van Rooij and Van den Eijnden 2007).

The rising popularity of the internet and the everincreasing amount of time adolescents spend online pose challenges to parents who want to protect their teenage children from excessive internet use (Greenfield 2004; Subrahmanyam et al. 2000; Wang et al. 2005). Parents worry about the one-sidedness and passivity of their children's leisure activity, and about possible health consequences such as obesity (Sothern 2004). Moreover, parents are sometimes confronted with the fact that their children have become so attached to the internet that they are no longer capable of controlling their online activity. In this regard, a growing body of literature is supporting the idea that, similarly to traditional addictive behaviors, adolescents as well as adults may develop an uncontrollable urge to use the internet, often accompanied by a loss of control, a preoccupation with internet use, and continued use despite negative consequences (Young 1998, 2004). Although there are aspects of this kind of online behavior that are different from the traditional view on addiction (e.g. there are no physical withdrawal symptoms), it can be argued that internet addiction, or Compulsive Internet Use (CIU) as we prefer to call it, has many similarities with substance abuse and pathological gambling according to the DSM-IV criteria (APA 1995; Mitchell 2000; Shapira et al. 2003). 
Several characteristics make the internet highly appealing such as easy availability, accessibility, affordability, and anonymity (Greenfield 1999). Particularly appealing is the possibility to rapidly achieve an intense emotional reward. Feeling socially connected and accepted may be such a reward for adolescents who make intensive use of the communication functions of the internet. In combination with the high availability of the internet, this feature facilitates persistence in the behavior (Cooper 1998; Orford 2001; Young et al. 1999).

Adolescents may be particularly vulnerable to the development of CIU. A recent Dutch study has shown that immediate online communication applications such as instant messaging and chatting bear a higher addictive potential than most other internet applications (Van den Eijnden et al. 2008). Instant messenger use is in fact the most popular internet function used by adolescents (Gross 2004; Van den Eijnden et al. 2008). In addition, the immaturity of the frontal cortical and subcortical monoaminergic brain systems is hypothesized to underlie adolescent impulsivity as a transitional trait behavior (Casey et al. 2008). On the one hand, this neurodevelopmental process seems to be functional by enhancing the learning drive, on the other hand these processes may lead to an increased vulnerability to addictive behaviors in adolescents (Chambers et al. 2003). It is the combination of enhanced susceptibility and the sheer popularity of internet applications with a highly addictive potential, such as instant online communication, which put youngsters more at risk of developing CIU.

Although no consensus exists on criteria for internet addiction and on measurement instruments, several studies report data on the prevalence of this relatively new phenomenon at less than $1 \%$ among undergraduates (Nichols and Nicki 2004) and almost $2 \%$ among a 12 -to-18-year-old representative sample of Norwegian (Johansson and Gotestam 2004) and Finn youth (Kaltiala-Heino et al. 2004). In addition, a recent Dutch study among a representative sample of adolescents aged 11-15 indicated that about 3.8\% of Dutch adolescents had developed serious symptoms of CIU (Van Rooij and Van den Eijnden 2007). In this study, CIU was described by criteria such as (1) continuation of internet use despite the intention or desire to stop or cut down; (2) experiencing unpleasant emotions when internet use is impossible; (3) using the internet to escape from negative feelings; (4) internet use dominating one's cognitions and behaviors; and (5) internet use resulting in conflict with others or in self-conflict (Meerkerk et al. 2009).

\section{Internet-specific Parenting}

Parents play an important role in the psychosocial development and well-being of their children. Numerous studies have addressed the impact of parenting practices on the development of problem behavior, such as substance use (e.g. Harakeh et al. 2004; Van der Vorst et al. 2005). Parents are important and influential agents, and their parenting practices may promote or prevent the development of internet-related problems.

Several studies have reported links between family characteristics and internet addiction. For instance, quality of the parent-child relationship was negatively associated with level of internet addiction among students (Liu and Kuo 2007), and parent-adolescent conflict (Yen et al. 2007) and lower satisfaction with family functioning (Ko et al. 2007; Yen et al. 2007) were positively related to adolescent internet addiction. However, few studies have addressed the link between actual parenting practices and children's internet use. In this regard, we only know about one survey among 222 children aged 10 to 12 , showing that restrictive parental techniques such as setting time limits and website restrictions are not related to children's actual internet use (Lee and Chae 2007). Hence whether internet-specific parenting practices can affect the risk of CIU is to a large extent unclear. The present study therefore addresses the connection between internet-specific parenting practices and CIU among adolescents. Since prior research lends some support to the importance of parental rule enforcement and parental reactions to adolescents' substance use (Luthar and Goldstein 2008; Otten et al. 2007a; Van der Vorst et al. 2006) we hypothesize that parental rule enforcement regarding internet use and parental reactions to excessive internet use are negatively related to CIU.

We further investigate the role of parental communication in adolescents' internet practices. Recent studies examined the role of parental communication in preventing alcohol use (Ennett et al. 2001; Jackson et al. 1999; Van der Vorst et al. 2005), and smoking (Harakeh et al. 2005; Otten et al. 2007a). Unexpectedly, some of these studies found positive associations between frequency of parental communication about alcohol use and smoking and adolescents' actual behavior (Van den Eijnden et al. 2008; Van der Vorst et al. 2006), whereas others found no associations (Ennett et al. 2001; Jackson et al. 1999). These results imply that frequent parental communication about substance use may increase adolescents' actual substance use behavior. On the other hand, these findings may also result from an opposite causal pathway whereby adolescents' substance use increases the frequency of parental communication about such use. Therefore, the present research will not only test associations between internet-specific parenting practices and CIU, but also the bidirectionality of the found associations.

Finally, recent studies have highlighted that, more than frequency of communication, quality of parental communication may be important in preventing adolescents' risk 
behaviors such as smoking (Harakeh et al. 2005) and alcohol use (Van den Eijnden et al. 2009). Therefore, the role of frequency and quality of parental communication regarding adolescents' internet use will be studied as well.

Associations between internet-specific parenting practices and CIU among adolescents were examined in two studies, namely: 1) a cross-sectional study using a large sample of 4,483 Dutch students aged 11-15, and 2) a longitudinal study using a sample of 510 Dutch adolescents aged 13-15. In both studies the hypothesis was tested that parental rule enforcement, parental reactions to excessive internet use and qualitatively good parental communication regarding adolescents' internet use are negatively related to CIU, whereas frequency of parental communication is positively related to CIU. In addition, the bidirectionality of these associations was tested using the longitudinal data of Study 2.

\section{Method}

\section{Procedure and Samples}

The data for Study 1 are collected as part of the first measurement of the Monitoring Study 'Internet and Youth' conducted by the Addiction Research Institute, Rotterdam. Data were collected among 15 elementary schools and nine secondary schools (with a total of 202 classrooms). By means of our sampling procedure we aimed to obtain a representative sample of Dutch adolescents aged 11 to 15 . The selection of schools was based on representative data about the distribution of Dutch schools with regard to school level (vocational training versus high school or preuniversity training), region in the Netherlands (north, east, south, west urban, west non-urban) and urbanization rate $(1=$ 'non-urban' to $5=$ 'highly urban') (www.cbs.nl). Because all classes of the participating schools were involved in this study, the final sample distribution was very similar to the population distribution with regard to gender, school level, region, urbanization rate and ethnic background. To illustrate this point, our sample consisted of $23 \%$ adolescents from ethnic minority groups, whereas $22 \%$ of adolescents in the general population belong to an ethnic minority group.

Prior to data collection, all school principals and teachers granted permission. Parents' permission was gathered by means of passive informed consent. More specifically, parents received a letter in which they were informed about the fact that their child's school was participating in a study on internet use and well-being, and that a questionnaire would be administered during school hours. If parents did not agree with their child's participation, they could contact either the school board or the researchers.
In February 2006, written questionnaires were administered in a classroom setting. Teachers received precise instructions about the classroom procedure, including guidelines to guarantee participants' privacy while filling out the questionnaire. Teachers were also asked to tell students about the confidentiality of participation in this study.

A total of 4,483 students participated in this study, $51.3 \%$ of them boys. Students' ages ranged between 10 years and 16 years $(M=13.1, \mathrm{SD}=1.15)$. Of the participants, $10.6 \%$ were in the fifth grade, $10.5 \%$ in the sixth grade, $40.3 \%$ in the seventh grade and $38.6 \%$ in the eighth grade. For students in the fifth and sixth grades, education was not differentiated into separate levels yet. Of the students in the seventh and eighth grades, 34\% were following vocational school and $49 \%$ were in high school or in a pre-university program (for $17 \%$ of the participants the school level was a combined version of these three school levels).

For Study 2, data were collected by means of banners on the internet. Adolescents who used MSN instant messenger received a banner, and adolescents aged 10 to 15 were asked to participate in a study on internet use. To ensure participation of both frequent and infrequent users of the messenger, banners were shown only once during a period of 6 weeks. At the end of the online questionnaire, participants were asked if they were willing to participate in a second measurement 6 months later, in which case they were asked for their e-mail address. Participants of the first measurement who agreed to volunteer in the second measurement as well received an e-mail with a link to the second online questionnaire 6 months later.

A total of 1,647 adolescents engaged in the first measurement, and 510 also engaged in the second measurement (response rate was $31 \%$ ). Of these 510 participants, $32.2 \%$ were male. Participants' age ranged from 10 years to 15 years, but $98.4 \%$ was 13,14 or 15 years old $(M=14.1, \mathrm{SD}=0.80)$. Of the participants, $28.5 \%$ were following vocational education, $26.7 \%$ were in high school, and $44.8 \%$ were in a pre-university program.

To examine whether drop-outs differed from students who participated in both measurements, we conducted a logistic regression analysis predicting participation in both measurements by gender, age, educational level, CIU and the five internet-specific parenting practices. Our findings only showed a significant association for educational level $(\mathrm{OR}=1.46, p<0.001,95 \% \mathrm{CI}$ between 1.30 and 1.64), indicating that students who participated in both measurements were more likely to follow a higher level of education, i.e. high school or pre-university training, compared to students who dropped out after the first measurement. No other differences were observed. 


\section{Measures}

The same measures were used in Studies 1 and 2 . Compulsive internet use was measured with an adapted version of the recently developed and validated Compulsive Internet Use Scale (CIUS) for adults (Meerkerk et al. 2009). This version contained ten of the 14 original items identifying the core features of CIU (see also Van den Eijnden et al. 2008), and another two items specifically addressing CIU among adolescents, e.g. going online at the expense of schoolwork. Answers were given on a 5-point scale ranging from 1 'never' to 5 'very often'. The mean score on all items was used. A high mean score indicated a high level of CIU. The scale showed good reliability in both studies (Study 1: Cronbach's alpha=0.85; Study 2: Cronbach's alpha $=0.84$ at $\mathrm{T} 1$ and 0.87 at T2).

Internet-specific parenting practices were measured using five newly developed scales (see "Appendix A" for the scale items). Rules with regard to time spent on the internet were measured with a 5-item scale containing three negative and two positive items (Study 1: Cronbach's alpha= 0.83; Study 2: Cronbach's alpha $=0.71$ at $\mathrm{T} 1$ and 0.75 at T2). Negative items were recoded so that high scores indicated strict parental rules with respect to time spent on the internet. Rules with regard to content of internet use were measured with a scale consisting of three negative items. The mean score on the recoded items was used. High scores on this scale indicated strong parental rules on the content of internet use. The scale showed good-to-moderate internal consistency (Study 1: Cronbach's alpha $=0.80$; Study 2: Cronbach's alpha $=0.76$ at $\mathrm{T} 1$ and 0.84 at T2). Reactions to excessive internet use were measured using a scale including six items, four positive and two negative (Study 1: Cronbach's alpha=0.85; Study 2: Cronbach's alpha $=0.89$ at $\mathrm{T} 1$ and 0.90 at T2). After recoding the negative items, a mean score was computed. A high mean score implied high levels of parental reactions to excessive internet use. A 3item scale was used to measure frequency of communication about internet use (Study 1: Cronbach's alpha=0.78; Study 2: Cronbach's alpha $=0.76$ at T1 and 0.75 at T2). A high mean score indicated a high frequency of parental communication about adolescents' internet use. In addition, a 3-item scale was used to measure quality of communication about internet use (Study 1: Cronbach's alpha=0.83; Study 2: Cronbach's alpha $=0.82$ at T1 and 0.85 at T2). A high mean score on this scale indicated a high perceived quality of parental communication about the internet.

An additional study by our research group recently provided some insight into the discriminant validity of the five internet-specific parenting measures, compared to general measures of parenting such as support (Scholte et al. 2003), behavioral control (Kerr and Stattin 2000), psychological control (Glasgow et al. 1997), and parent- child attachment (Armsden and Greenburg 1987). To the degree that significant multivariate associations were found between these general parenting measures and the internetspecific parenting measures, these associations were low to moderately high (varying between $\beta=0.10$ and $\beta=0.28$ ) (Van Rooij and Van den Eijnden 2007). These data suggest that the internet-specific parenting constructs used in this study differ from general parenting constructs such as support and behavioral control, and that they measure unique aspects of parenting practices.

\section{Strategy of Analyses}

To answer the first research question, we used both datasets (Studies 1 and 2) and computed correlations between the five indicators for internet-specific parenting practices and CIU. We further tested cross-sectional and longitudinal relations between internet parenting and CIU by means of structural equation modeling (SEM) using the software package MPLUS version 4.2 (Muthén and Muthén 1998). A model was tested including CIU as dependent variable and the five internet-specific parenting practices as independent variables (see Fig. 1). Age, gender and educational level were included as control variables.

In our SEM analyses four models were tested, one for the sample of Study 1 (cross-sectional) and three for the sample of Study 2 (two cross-sectional and one longitudinal). The respondents of Study 1 are nested within classrooms and schools. To correct for interdependency of these data, we applied a correction procedure (known as the COMPLEXTWOLEVEL procedure in MPLUS) to get unbiased estimates of the standard errors of the parameters. However, anticipating the results of the SEM-analyses we found that the combined procedure didn't work due to limited memory

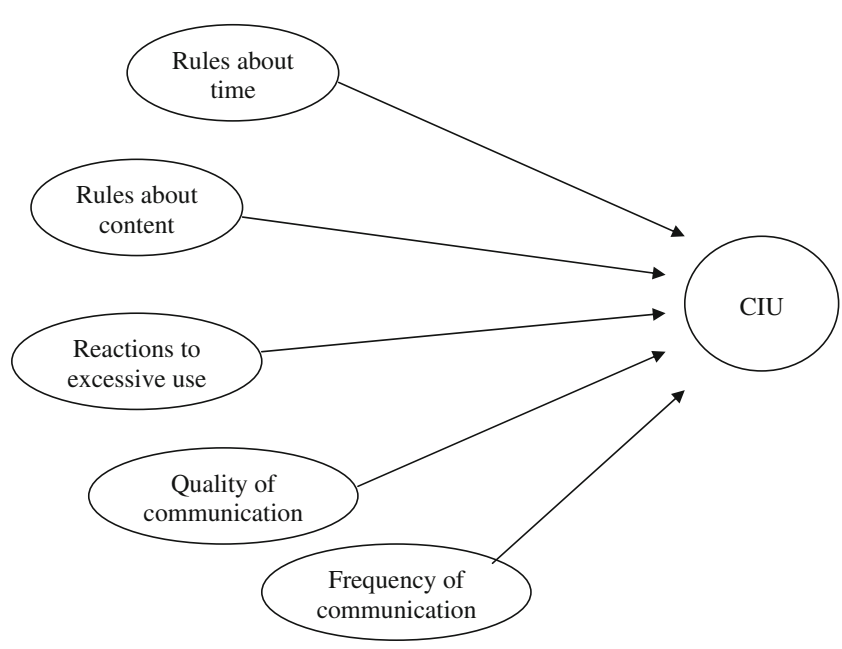

Fig. 1 Cross-sectional relations between internet-specific parenting and CIU 
space. For that reason we applied the COMPLEX procedure for schools and classrooms separately and compared both results (De Leeuw et al. 2008). The differences between the two SEModels were negligible. The Intraclass Correlation Coefficient (ICC) for the dependent variables in the model varied between 0.01 and 0.11 for schools and between 0.01 and 0.13 for classrooms.

The six latent variables could adequately be represented by their original items in the first sample of 4,483 respondents (Study 1). However, the sample of Study 2 consisted of 510 respondents and for this sample it was better to use parcels as indicators for the latent variables, to prevent the number of estimated parameters from being too high for the sample size. To be able to compare findings between Study 1 and Study 2, we decided to use parcels for the sample of Study 1 too. A parcel is the sum or the mean of a subset of items of a variable. Rules regarding time spent on the internet were measured by two parcels, each consisting of two items and one additional item; parental reactions to excessive internet use by three parcels, each containing two items; and CIU by three 4-item parcels. There are several ways to create parcels. In this case we tried to create parcels reflecting the latent variable in a more or less equivalent way in terms of item factor loadings. For each measure the factor loadings of the 1-factor solution were inspected and items were allocated to parcels according to the magnitude of the factor loadings. Each parcel contained items with higher and lower factor loadings reflecting the original factor structure (see also Huver et al. 2007). For rules regarding time spent on the internet three indicators were used, two parcels and one item. The item had the highest factor loading. For the longitudinal study, the same subset of items was used over time to get equivalent latent variables. In this way, we created three indicators (three parcels or three items) for each latent variable. Fewer indicators may cause undesirable results, such as factor loadings $>1$, leading to negative error variances.

Prior to the final SEM analyses, the measurement part, i.e. the factor model, was tested. All three cross-sectional factor models showed a good fit with CFI $>0.97$ and RMSEA $<0.05$. The factor loadings for the three models varied between 0.54 and 0.92 , indicating that the indicators were a good representation of their latent variables. The percentage of missing values varied between $0.05 \%$ and $3.2 \%$ in the sample of Study 1. To utilize all available information in the data, we used the Full Information Maximum Likelihood (FIML) estimator. For Study 2 we used the ML estimator because there were no missing values. We reported the model fit with two fit measures as recommended by several authors: (a) the Root Mean Square Error of Approximation (RMSEA) (Byrne 1998) and (b) the Comparative Fit Index (CFI) of Bentler (Marsh et al.
1988). RMSEA is used to assess approximate fit, preferably with values lower than or equal to 0.05 , but values between 0.05 and 0.08 are indicative of a fair fit (Kaplan 2000). CFI is a comparative fit index; values above 0.95 are preferred (Kaplan 2000) but should not be lower than 0.90 (Kline 1998).

To answer the second research question, we used longitudinal data of Study 2 and examined cross-lagged paths by using SEM. Cross-lagged panel analyses (Finkel 1995) were conducted, i.e. whereby CIU and internet-specific parenting practices at $\mathrm{T} 1$ were predictors of the corresponding variables at $\mathrm{T} 2$. The aim of cross-lagged analysis using panel data was to determine which cross-relation is predominant (Finkel 1995). The strength of the associations between CIU at $\mathrm{T} 1$ and $\mathrm{T} 2$ and between internet-specific parenting practices at $\mathrm{T} 1$ and $\mathrm{T} 2$ gave an indication of the stability of these concepts over time. Significant crossrelations over time gave an indication of predominance. For instance, if the path from internet-specific parenting practices at $\mathrm{T} 1$ to $\mathrm{CIU}$ at $\mathrm{T} 2$ was significant, whereas the path from $\mathrm{CIU}$ at $\mathrm{T} 1$ to internet-specific parenting practices at $\mathrm{T} 2$ was non-significant, it would imply that of the two cross-paths the relation from internet-specific parenting practices to CIU is predominant. The cross-lagged analyses were performed with gender, age and school level at T1 as control variables.

\section{Results}

Internet Use in Both Samples

In both studies, almost all participants (Study 1: 99.5\%, Study 2: 100\%) reported using the internet and having internet access at home (Study 1: 96.6\%; Study 2: 99.0\%). In Study 1, less than half of the sample (43\%) used the internet 7 days a week, $25.1 \%$ was using the internet 5 days or 6 days a week, $23.6 \% 2-4$ days a week, and $8.3 \% 1$ day a week or less. In Study 2, most participants used the internet 7 days a week (64\%), 24\% was using the internet 5 days or 6 days a week, and $12 \% 4$ days a week or less. In both studies the most frequently used internet function was instant messaging, followed by e-mail, searching for information, downloading music, films or software, and gaming. In Study 1, participants reported using the internet for $11 \mathrm{~h}$ a week on average $(\mathrm{SD}=11,68)$, in Study 2 this was $14.8 \mathrm{~h}$ a week $(\mathrm{SD}=11.16)$ on $\mathrm{T} 1$ and $14.3 \mathrm{~h}$ a week $(\mathrm{SD}=10.58)$ on $\mathrm{T} 2$. The mean level of CIU in Study 1 was 1.82 (range 3.79). Within study 2 , the mean level of CIU was 2.11 (range 3.75) on $\mathrm{T} 1$ and 2.00 (range 4.00) on $\mathrm{T} 2$. On basis of the criteria used to classify compulsive internet use as described by Meerkerk (2007), the prevalence of compulsive internet use was $4.2 \%$ in Study 1 , and $8 \%$ and $6.5 \%$ at $\mathrm{T} 1$ and $\mathrm{T} 2$ respectively in Study 2 . The two studies, 
thus, account for a broad range of scores on the CIUS and also include problematic levels of internet use, whereby symptoms of compulsive use are more prevalent in the sample of Study 2.

Correlations Between Internet-specific Parenting Practices and CIU

Correlations between internet-specific parenting practices and CIU are shown in Table 1. Both studies showed negative cross-sectional and longitudinal relations between quality of parental communication about the internet and CIU, and positive cross-sectional and longitudinal correlations between parental rules about time spent on the internet and CIU. Only cross-sectional (but not longitudinal) correlations were found between parental rules about internet content and CIU, showing a negative association. Finally, within Study 1 (but not Study 2) we found a negative crosssectional correlation between parental reactions to excessive internet use and CIU.

Cross-sectional and Longitudinal Relations Between Internet Parenting Practices and CIU: SEM Analyses

Relations between internet-specific parenting practices and CIU, while controlling for demographic characteristics, were further examined by conducting SEM analyses. The cross-sectional model for Study 1 explained $22.4 \%$ of the variance in CIU, whereas the cross-sectional models for Study 2 explained respectively $19.3 \%$ and $28.9 \%$. According to the model for Study 1, four parenting practices were associated with CIU. ${ }^{1}$ Contrary to our expectations, parental rules about time spent on the internet was positively related to $\mathrm{CIU}$, indicating that the more parents enforced rules regarding time online, the higher the risk of CIU. In line with our expectations, parental reactions to excessive internet use, parental rules about the content of internet use, and quality of parental communication about internet use were negatively related to CIU. When adolescents reported that their parents would respond to their excessive internet use, that their parents enforce rules about the content of their internet use, and that they had satisfying conversations with their parents on internet use, they were at a lower risk of CIU. Finally, frequency of communication was not significantly related to CIU. The cross-sectional models of Study 2 showed similar associations to those found in Study 1 (Table 2).

\footnotetext{
${ }^{1}$ In a recent cross-sectional study (Van Rooij and Van den Eijnden 2007), we investigated whether associations with internet-specific parenting are similar for 'weekly time spent online' and for CIU as the dependent variable. The results showed fewer and weaker crosssectional associations for 'weekly time spent online', in comparison to CIU.
}

The longitudinal model of Study 2 not including CIU T1 as a control variable showed similar associations to the cross-sectional models of Study 2, except that no relation was found between rules about content and CIU. Finally, the longitudinal model of Study 2 including CIU at T1 as a control variable did not show any significant associations anymore.

As presented in Table 3, SEM analyses for Study 1 show weak or no associations between the control variables age $(\beta=0.05)$, gender $(n s$.$) and educational level (\beta=-0.06)$ and CIU. The two cross-sectional models of Study 2, however, showed negative associations between the control variables of age and school level and CIU, implying that younger adolescents and adolescents with a lower educational level showed more symptoms of CIU. In addition, all models showed associations between the control variables and internet-related parenting, whereby girls scored higher than boys on all internet-specific parenting practices (Study 2 showed no associations between gender and quality of communication), younger respondents scored higher on four of the five internet-related parenting practices than older respondents (no link was found between age and quality of communication), and respondents with a higher educational level reported more rules regarding time spent on the internet, more parental reactions to excessive internet use, a higher quality of parental communication about the internet (only Study 1) and a higher frequency of communication about internet use (only Study 2).

\section{Bidirectionality of Associations Between Internet-specific Parenting Practices and CIU}

To test whether internet-specific parenting practices predicted future CIU, or whether CIU predicted future internet-specific parenting practices, five cross-lagged panel analyses were conducted, each including one of the five internet-specific parenting practices. Age, gender and school level were linked to the four model variables to control for their effect. The results are given in Fig. 2. The fit measures of the five models were satisfactory with CFI $>0.95$ and RMSEA $<0.05$. Two models showed significant cross-lagged pathways. First of all, the model including quality of communication about internet use showed a significant pathway from quality of communication at $\mathrm{T} 1$ to $\mathrm{CIU}$ at $\mathrm{T} 2(\beta=-0.10)$. Such a pathway was not shown from CIU at $\mathrm{T} 1$ to quality of communication at $\mathrm{T} 2$. These findings imply that quality of parental communication about internet use decreased the risk of developing future CIU. Second, a significant cross-lagged pathway was found from CIU at $\mathrm{T} 1$ to frequency of communication at T2 $(\beta=-0.13)$. Such a pathway was not shown from frequency of communication at $\mathrm{T} 1$ to $\mathrm{CIU}$ at T2. These results indicate that CIU among adolescents decreases parents' frequency of communication about 


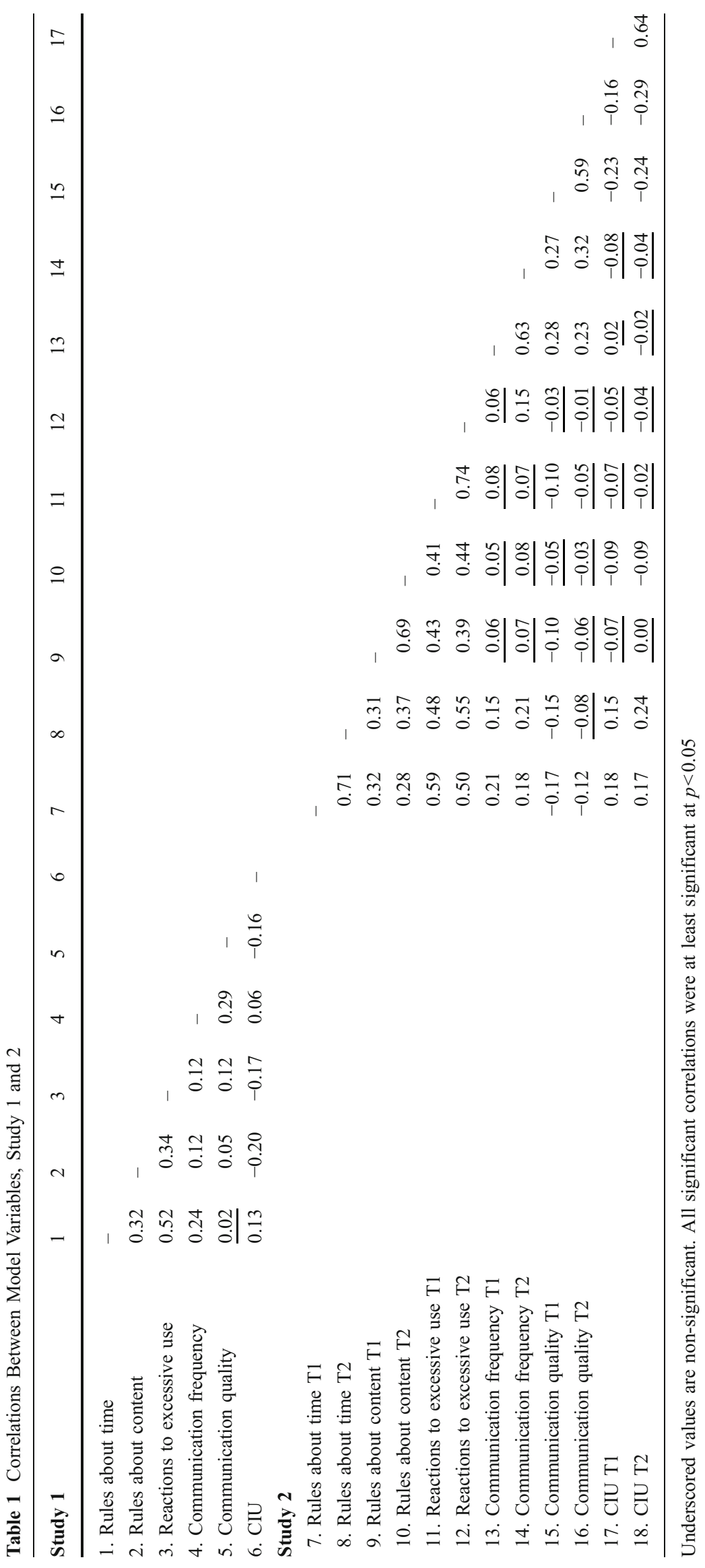


Table 2 Relations Between Internet-specific Parenting Practices and CIU (Standardized Gamma Weights)

\begin{tabular}{|c|c|c|c|c|c|}
\hline & \multicolumn{3}{|c|}{ Cross-sectional model } & \multicolumn{2}{|c|}{ Longitudinal model } \\
\hline & \multirow{2}{*}{$\begin{array}{l}\text { Study } 1 \\
\text { CIU }\end{array}$} & \multicolumn{2}{|l|}{ Study 2} & \multicolumn{2}{|l|}{ Study 2} \\
\hline & & CIU T1 & CIU T2 & CIU T2 & CIU T2 controlling for CIU T1 \\
\hline CIU T1 & - & - & - & - & 0.64 \\
\hline Rules about time & 0.43 & 0.36 & 0.45 & 0.37 & 0.08 \\
\hline Rules about content & -0.29 & -0.19 & -0.31 & -0.07 & 0.05 \\
\hline Reactions to excessive use & -0.33 & -0.24 & -0.14 & -0.22 & -0.07 \\
\hline Frequency of communication & 0.09 & 0.03 & -0.00 & -0.01 & -0.03 \\
\hline Quality of communication & $\overline{-0.16}$ & $\overline{-0.24}$ & $\overline{-0.28}$ & $\overline{-0.23}$ & $\overline{-0.07}$ \\
\hline
\end{tabular}

Underscored values are non-significant

Study $1 \mathrm{Tl}$ : $\chi^{2}(154)=1196.54, p=0.000$, RMSEA $=0.039, \mathrm{CFI}=0.967, \%$ expl. variance in $\mathrm{CIU}=22.4 \%$

Study 2 T1: $\chi^{2}(154)=333.92, p=0.000, \mathrm{RMSEA}=0.048, \mathrm{CFI}=0.960, \%$ expl. variance in CIU: $19.3 \%$

Study 2 T2: $\chi^{2}(154)=308.62, p=0.000$, RMSEA $=0.044, \mathrm{CFI}=0.970, \%$ expl. variance in CIU: $28.9 \%$

Study 2 T1-T2: $\chi^{2}(154)=317.94, p=0.000$, RMSEA $=0.046, \mathrm{CFI}=0.965, \%$ expl. variance in CIU: $15.2 \%$

Study 2 T1-T2: $\chi^{2}(205)=395.04, p=0.000$, RMSEA $=0.043, \mathrm{CFI}=0.967, \%$ expl. variance in CIU: $48.5 \%$ (controlled for CIU T1)

internet use. The fit measures of these two models were satisfactory. The results for the variables of gender, age and school level are not presented here because they showed identical effects as reported in the longitudinal models of Table 3.

\section{Discussion}

The two present studies provide more insight into the role parents can play to prevent their teenage children from developing compulsive internet use (CIU). Internet-specific

Table 3 Relations Between Participants' Demographic Characteristics, Internet-specific Parenting Practices and CIU (Standardized Gamma Weights)

\begin{tabular}{|c|c|c|c|c|c|c|}
\hline & Rules about time & Rules about content & $\begin{array}{l}\text { Reactions to } \\
\text { excessive use }\end{array}$ & $\begin{array}{l}\text { Frequency of } \\
\text { communication }\end{array}$ & $\begin{array}{l}\text { Quality of } \\
\text { communication }\end{array}$ & $\mathrm{CIU}$ \\
\hline \multicolumn{7}{|c|}{ Cross-sectional model: Study 1} \\
\hline Gender & 0.10 & 0.14 & 0.09 & 0.20 & 0.09 & 0.03 \\
\hline Age & -0.23 & -0.28 & -0.25 & -0.04 & -0.07 & 0.05 \\
\hline School level & 0.10 & -0.06 & 0.15 & -0.01 & 0.08 & -0.06 \\
\hline \multicolumn{7}{|c|}{ Cross-sectional model: Study 2 T1 } \\
\hline Gender & 0.16 & 0.16 & 0.10 & 0.13 & 0.06 & 0.04 \\
\hline Age & $\underline{-0.06}$ & -0.18 & -0.11 & 0.06 & 0.05 & -0.10 \\
\hline School level & 0.08 & $\underline{-0.08}$ & 0.17 & 0.13 & 0.08 & -0.15 \\
\hline \multicolumn{7}{|c|}{ Cross-sectional model: Study 2 T2 } \\
\hline Gender & 0.17 & 0.16 & 0.14 & 0.26 & 0.05 & 0.05 \\
\hline Age & -0.14 & -0.15 & -0.09 & 0.05 & 0.04 & -0.11 \\
\hline School level & 0.04 & 0.09 & 0.20 & 0.13 & 0.08 & -0.11 \\
\hline \multicolumn{7}{|c|}{ Longitudinal model: Study $2 \mathrm{~T} 1-\mathrm{T} 2$} \\
\hline Gender & 0.16 & 0.16 & 0.10 & 0.13 & 0.06 & 0.04 \\
\hline Age & $\underline{-0.06}$ & -0.18 & -0.11 & 0.06 & 0.05 & -0.13 \\
\hline School level & 0.08 & 0.08 & 0.17 & 0.13 & 0.08 & -0.11 \\
\hline \multicolumn{7}{|c|}{ Longitudinal model: Study $2 \mathrm{~T} 1-\mathrm{T} 2$ controlling for CIU T1 } \\
\hline Gender & 0.16 & 0.16 & 0.10 & 0.14 & 0.06 & 0.01 \\
\hline Age & $\underline{-0.06}$ & -0.18 & -0.11 & 0.06 & 0.05 & -0.07 \\
\hline School level & 0.08 & 0.08 & 0.17 & 0.13 & 0.08 & -0.02 \\
\hline
\end{tabular}

Underscored values are non-significant 
Fig. 2 Relations between internet specific parenting practices and CIU: cross lagged Models based on Data of Study 2

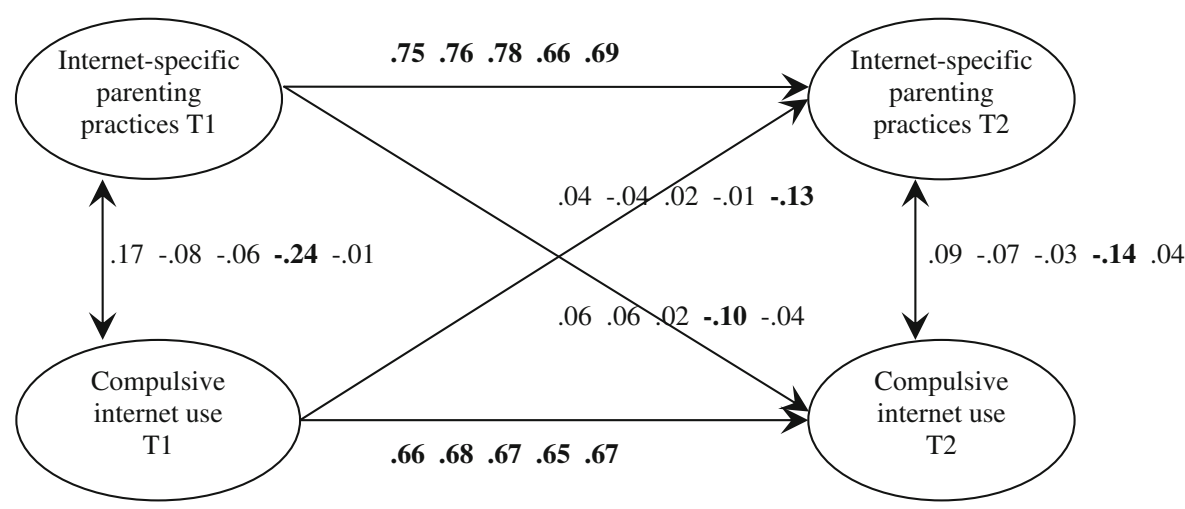

Rules about time: $\chi^{2}(66)=91.86 \mathrm{p}=.019 \mathrm{CFI}=.993 \mathrm{RMSEA}=.028$

Rules about content: $\chi^{2}(66)=124.54 \mathrm{p}=.000 \mathrm{CFI}=.984$ RMSEA $=.042$

Reactions to excessive use: $\chi^{2}(66)=101.26 \mathrm{p}=.003 \mathrm{CFI}=.992$ RMSEA $=.032$

Quality of communication: $\chi^{2}(66)=145.64 \mathrm{p}=.000 \mathrm{CFI}=.978$ RMSEA $=.049$

Frequency of communication: $\chi^{2}(66)=137.54 \mathrm{p}=.000 \mathrm{CFI}=.978$ RMSEA $=.046$

Note 1: The figures refer to the models with rules about time (first), rules about content (second), reactions to excessive use (third), quality of communication (fourth) and frequency of communication (fifth) respectively.

Note 2: Figures in bold are significant with $p$ at least $<.05$.

Note 3: The figures at $T 1$ are correlations between latent variables, at $T 2$ correlations between the disturbance terms of the latent variables. The remaining figures are standardized regression weights. parenting practices may help prevent CIU among adolescents. More specifically, the findings of the present studies provide some evidence that quality of parental communication about internet use is an effective tool to prevent CIU. All cross-sectional SEM models and two of the three longitudinal SEM models support the assumption that youngsters who feel comfortable, understood and taken seriously by their parents during conversations about their internet use have a lower risk of developing CIU. This finding is in line with previous studies on parenting and adolescent substance use showing positive concurrent and longitudinal associations between quality of parental communication and the target behavior (Otten et al. 2007b; Spijkerman et al. 2008). In addition, a longitudinal study showed that quality of communication by the mother was negatively related to adolescents' alcohol use, whereas quality of communication by the father was not (Van den Eijnden et al. 2009), and a second study suggested that quality of parental communication precedes adolescents' smoking cognitions and thereby helps to prevent early adolescent smoking onset (Otten et al. 2007b). The authors concluded that communication patterns based on mutual respect and equality help prevent adolescents' substance use.

Although the present data provide some evidence for a negative association between quality of communication and $\mathrm{CIU}$, one may reason that this negative association may-at least partly - result from associations between general family relations such as quality of parent-child attachment (Armsden and Greenburg 1987) and CIU. However, a recent study on the relationship between parenting practices and adolescent smoking trajectories does not support this assumption. Although there was a relationship between quality of parental communication and one of the general parenting dimensions, i.e. parental support, the negative relationship between quality of communication and adolescents' smoking trajectories remained while controlling for this inter-correlation between parental support and quality of communication (De Leeuw et al. 2009). More importantly, results from a cross-sectional study by our research group among 4,870 adolescents aged 11-16 do not support this assumption either (Van Rooij and Van den Eijnden 2007). In the first place, these data hardly show any associations between general parenting practices (i.e. quality of parent-child attachment, support, behavioral control and psychological control) and CIU. Secondly, these data only demonstrate low-to-moderate associations between general parenting practices and internet-related parenting. Finally, mediation analyses (cf. Baron and Kenny 1986) do not support the idea that internet-related parenting practices mediate the relationship between general parenting practices and CIU. These findings therefore indicate that quality of communication about internet use uniquely predicts CIU over and above the impact of general parenting practices.

Although the impact of quality of parental communication appears most noteworthy, other parental practices also seem to be related to the development of adolescents' CIU. When tested within the cross-sectional models, both parental reactions to excessive use and parental rules regarding 
content of internet use showed negative associations with $\mathrm{CIU}$, suggesting that parental reactions to excessive internet use and parental rules regarding the content of internet use may help to decrease the risk of developing CIU among adolescents.

The data also yielded interesting results with regard to the possible impact of adolescents' CIU on internet-related parenting behavior. The cross-lagged analyses showed a significant negative path from CIU at $\mathrm{T} 1$ to frequency of parental communication at $\mathrm{T} 2$, implying that compulsive internet-using adolescents report less frequently conversations about internet use with their parents 6 months later. This finding may reflect the fact that parents, after a while, give up the hope of being able to positively affect their children's' compulsive tendencies simply by discussing the subject with them. And parents may even be right about this point, since the present study provides no support for the idea that frequent communication about the child's internet habits would be a useful parenting practice.

Unexpectedly, the cross-sectional data of the present study show that parental rules about time spent online were positively related to $\mathrm{CIU}$, suggesting that more and stricter rules about time may promote the development of CIU. An alternative explanation would be that $\mathrm{CIU}$ among adolescents may stimulate stricter rule enforcement regarding online time among parents. Unfortunately, cross-lagged panel analysis did not yield support for either one of these two directional pathways. Nevertheless, it should be noted that the positive cross-sectional association between parental rules and CIU contrasts with the consistent findings in the field of alcoholspecific parenting, showing that parental rule enforcement regarding alcohol use helps prevent adolescents' early drinking behavior (Spijkerman et al. 2008; Van der Vorst et al. 2005; Van Zundert et al. 2006).

The positive association between rules regarding time and CIU may also explain the finding that no significant bivariate correlation was found between parental reactions to excessive internet use and CIU, while the three SEM models did show significant negative associations between parental reactions and CIU. May be the high positive intercorrelation between parental reactions to excessive internet use and rules regarding time online suppresses the bivariate correlation between parental reactions and CIU. If so, it should be concluded that parental reactions to excessive use may be an effective tool to prevent CIU, but only in case parental reactions do not consist of setting strict time limits. Future research, however, is required to draw more definite conclusions on the role of different aspects of parental reactions to excessive internet use in preventing CIU.

Before discussing the strengths of these studies, we first want to mention some limitations. First, in the absence of existing measurement instruments we developed five new scales to measure different aspects of internet-specific parenting. Although previous findings indicate that these internet-specific parenting scales measure unique aspects of parenting not captured by frequently used measures of general parenting (Van Rooij and Van den Eijnden 2007), research using these internet-specific parenting measures would benefit from a more thorough assessment of the validity of these internet-specific parenting scales.

Moreover, the present data were based on adolescents' self-reports and did not include reports from parents. Recent studies indicate discrepancies between parents' and adolescents' reports on substance use (Engels et al. 2007), and emotional and behavioral problems (Ferdinand et al. 2004; Vierhaus and Lohaus 2008). These studies further demonstrate that parental and adolescents' self-reports differ in their prediction of the target behaviors depending, for example, on the type of behavior that was predicted and adolescents' gender (Vierhaus and Lohaus 2008). It is also shown that parents who underestimated their children's alcohol use knew less about their children's whereabouts and enforced less parental control than parents who did not underestimate their children's alcohol use (Engels et al. 2007). Hence, discrepancies in parent-child reports may indicate a specific type of parenting style that is related to risky adolescent behavior. In light of the present findings, we should bear in mind that adolescents' perceptions about their own internet habits and their parents' parenting practices may differ from parental perceptions about these topics. Future research should further examine this issue by incorporating data from adolescents as well as their parents.

Furthermore, it should be noted that the time lag of our longitudinal study was 6 months. This may be a rather long period to find effects of parenting on CIU and vice versa. For example, if adolescents spent increasing time on the internet, parents may start to discuss this with their teenage children. However, this will probably occur within days or weeks after parents start to worry. Within a time frame of 6 months, however, the frequency of communication about internet use may have decreased again. Thus, such shortterm effects may not be demonstrated with the present longitudinal design. Therefore, to further enhance our knowledge on the effectiveness of internet-specific parenting, it would be helpful if future research would model individual trajectories of CIU in relation to internet-specific parenting practices, using at least three or four short-term follow up measurements.

Another limitation is the high drop-out rates between the first and second measurements of Study 2, and the fact that the attrition analysis showed a possible over-representation of higher educated adolescents at the second measurement. Since the results of Study 1 suggest that CIU is more prevalent among lower educated adolescents, some caution is warranted when generalizing the findings of the crosslagged analyses to the general adolescent population. 
Finally, we should bear in mind that the data of Study 2 were based on a selective sample of participants who were recruited through the internet, more specifically through MSN messenger. As a result, those youngsters who do not use MSN messenger were excluded from participation in this study, thereby also limiting its external validity. It should be noted, however, that recent data show that about $86 \%$ of adolescents aged $11-15$ use MSN messenger for $7 \mathrm{~h}$ to $8 \mathrm{~h}$ a week on average (Van Rooij and Van den Eijnden 2007). Because banners were given only once during a period of 6 weeks, both frequent and less frequent users of MSN messenger were recruited. We therefore assume that the external validity of the present findings is not seriously harmed. This idea is further supported by the finding that the average time adolescents spent online in Study 2 was more or less similar to that of Study 1 among a representative sample of Dutch secondary school children in the same age group.

In sum, qualitatively good communication about internet use seems to be the most promising tool for parents to prevent their teenage children from developing a pattern of CIU. The strength of the present study is that we examined relations between parenting practices and CIU on the basis of cross-sectional data of a large, representative sample of adolescents and longitudinal data of a smaller sample using advanced statistics to examine bidirectional pathways. Previous authors already suggested a link between parenting behavior and problematic internet use (Lee and Chae 2007; Wang et al. 2005; Yen et al. 2007). However, this is the first study testing longitudinal relations between internet-specific parenting practices and CIU. The present study further contributes to current knowledge on determinants of CIU by showing the impact of several forms of internet-specific parenting practices, and provides a more complete framework for studying internet-specific socialization based on empirical insights on parenting practices and adolescents' substance use.

Open Access This article is distributed under the terms of the Creative Commons Attribution Noncommercial License which permits any noncommercial use, distribution, and reproduction in any medium, provided the original author(s) and source are credited.

\section{Appendix A}

Item

Answer categories

Rules regarding time online

1 My parents allow me to go on the 1. 'Absolutely not true' internet as often as I want to.

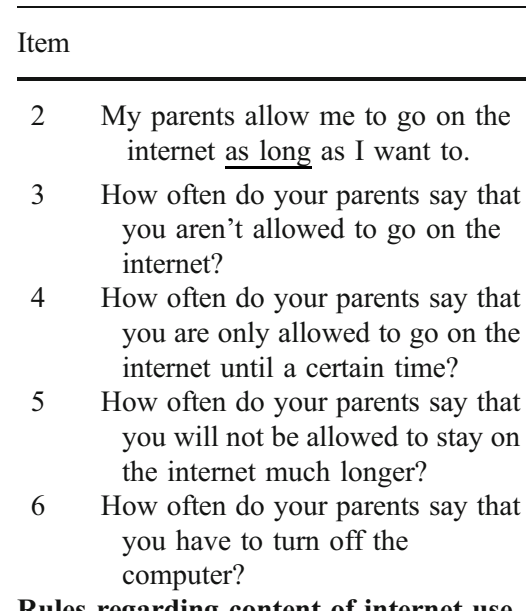

Answer categories

1. 'Absolutely not true' to 5. 'Absolutely true'

1. 'Never' to 5. 'Very often'

1. 'Never' to 5. 'Very often'

1. 'Never' to 5 . 'Very often'

1. 'Never' to 5. 'Very often'

Rules regarding content of internet use

1 My parents allow me to do whatever I like on the internet.

2 My parents allow me to visit every website that I want.

1. 'Absolutely not true' to 5. 'Absolutely true'

1. 'Absolutely not true' to 5. 'Absolutely true'

1. 'Absolutely not true' to 5. 'Absolutely true'

\section{Reactions to excesive internet use}

If you were on the internet for an entire weekend day, how would your parents react?

1 They would allow it.

1. 'Absolutely not' to 5 . 'Absolutely'

2 They would forbid it.

1. 'Absolutely not' to 5 . 'Absolutely'

3 They would make remarks about it

1. 'Absolutely not' to 5 . 'Absolutely'

4 They would intervene.

1. 'Absolutely not' to 5 . 'Absolutely'

5 They would give me a lecture.

6 They would allow me to go on.

1. 'Absolutely not' to 5 . 'Absolutely'

1. 'Absolutely not' to 5 . 'Absolutely'

\section{Frequency of communication regarding internet use}

1 How often do you and your parents talk about what you are doing on the internet?

2 How often do you and your parents talk about the time you spend on the internet?

3 How often do you and your parents 1. 'Never' to 5. 'Very

talk about who you have internet often' contact with?

1. 'Never' to 5. 'Very often'

1. 'Never' to 5. 'Very often'

\section{Quality of communication regarding internet use}

When my parents and I talk about my internet use,

1 I feel comfortable.

1. 'Absolutely not true' to 5. 'Absolutely true'

2 I feel understood.

1. 'Absolutely not true' to 5. 'Absolutely true'

3 I feel taken seriously.

'Absolutely not true' to 5. 'Absolutely true' 


\section{References}

APA. (1995). Practice guidelines for the treatment of patients with substance use disorder: Alcohol, cocaine, opiates. American Journal of Psychiatry, 152(Suppl).

Armsden, G. C., \& Greenburg, M. T. (1987). The inventory of parent and peer attachment: Individual differences and their relationship to psychological well-being in adolescence. Journal of Youth and Adolescence, 16(5), 427-454.

Baron, R. M., \& Kenny, D. A. (1986). The moderator-mediator variable distinction in social psychological research: conceptual, strategic and statistical considerations. Journal of Personality and Social Psychology, 51, 1173-1182.

Byrne, B. M. (1998). Structural equation modeling with LISREL, PRELIS and SIMPLIS: Basic concepts, applications, and programming. Mahwah: Erlbaum.

Chambers, R. A., Taylor, J. R., \& Potenza, M. N. (2003). Developmental neurocircuitry of motivation in adolescence: a critical period of addiction vulnerability. American Journal of Psychiatry, 160(6), 1041-1052.

Casey, B. J., Jones, R. M., \& Hare, T. A. (2008). The adolescent brain. Annals of the New York Academy of Sciences, 1124, 111-126.

Cooper, A. (1998). Sexuality and the Internet: surfing into the new millennium. CyberPsychology \& Behavior, 1(2), 187-193.

De Leeuw, R. N. H., Scholte, R. H. J., Harakeh, Z., Van Leeuwe, J. F. J., \& Engels, R. C. M. E. (2008). Parental smokingspecific communication, adolescents' smoking behavior and friendship selection. Journal of Youth and Adolescence, 37(10), $1229-1241$.

De Leeuw, R. N., Scholte, R. H., Vermulst, A. A., \& Engels, R. C. M. E. (2009). The relation between smoking-specific parenting and smoking trajectories of adolescents: How are changes in parenting related to changes in smoking?

Engels, R. C. M. E., Van der Vorst, H., Dekovic, M., \& Meeus, W. (2007). Correspondence in collateral and self-reports on alcohol consumption: a within family analysis. Addictive Behaviors, 32 (5), 1016-1030

Ennett, S. T., Bauman, K. E., Pemberton, M., Foshee, V. A., Chuang, Y. C., King, T. S., et al. (2001). Mediation in a family-directed program for prevention of adolescent tobacco and alcohol use. Preventive Medicine, 33(4), 333-346.

Ferdinand, R. F., Van der Ende, J., \& Verhulst, F. C. (2004). Parentadolescent disagreement regarding psychopathology in adolescents from the general population as a risk factor for adverse outcome. Journal of Abnormal Psychology, 113(2), 198-206.

Finkel, S. E. (1995). Causal analysis with panel data (Vol. 105). Thousand Oaks: SAGE.

Glasgow, K. L., Dornbusch, S. M., Troyer, L., Steinberg, L., et al. (1997). Parenting styles, adolescents' attributions, and educational outcomes in nine heterogeneous high schools. Child Development, 68(3), 507-529.

Greenfield, D. N. (1999). Psychological characteristics of compulsive Internet use: a preliminary analysis. CyberPsychology \& Behavior, 2(5), 403-412.

Greenfield, P. M. (2004). Developmental considerations for determining appropriate internet use guidelines for children and adolescents. Journal of Applied Developmental Psychology, 25(6), $751-762$

Gross, E. F. (2004). Adolescent Internet use: what we expect, what teens report. Journal of Applied Developmental Psychology, 25 (6), 633-649.

Harakeh, Z., Scholte, R. H., Vermulst, A. A., De Vries, H., \& Engels, R. C. M. E. (2004). Parental factors and adolescents' smoking behavior: an extension of The theory of planned behavior. Preventive Medicine, 39(5), 951-961.
Harakeh, Z., Scholte, R. H., De Vries, H., \& Engels, R. C. M. E. (2005). Parental rules and communication: their association with adolescent smoking. Addiction, 100(6), 862-870.

Huver, R. M. E., Engels, R. C. M. E., Vermulst, A. A., \& DeVries, H. (2007). Is parenting style a context for smoking-specific parenting practices? Drug and Alcohol Dependence, 89, 116125.

Jackson, C., Henriksen, L., \& Dickinson, D. (1999). Alcohol-specific socialization, parenting behaviors and alcohol use by children. Journal of Studies on Alcohol, 60(3), 362-367.

Johansson, A., \& Gotestam, K. G. (2004). Internet addiction: characteristics of a questionnaire and prevalence in Norwegian youth (12-18 years). Scandinavian Journal of Psychology, 45(3), 223-229.

Kaltiala-Heino, R., Lintonen, T., \& Rimpela, A. (2004). Internet addiction? Potentially problematic use of the Internet in a population of 12-18 year-old adolescents. Addiction Research and Theory, 12(1), 89-96.

Kaplan, D. (2000). Structural equation modeling: Foundations and extensions. Sage: Thousand Oaks.

Kerr, M., \& Stattin, H. (2000). What parents know, how they know it, and several forms of adolescent adjustment: further support for a reinterpretation of monitoring. Developmental Psychology, 36(3), 366-380.

Kline, R. B. (1998). Principles and practices of structural equation modeling. New York: Guilford.

Ko, C. H., Yen, J. Y., Yen, C. F., Lin, H. C., \& Yang, M. J. (2007). Factors predictive for incidence and remission of internet addiction in young adolescents: a prospective study. CyberPsychology \& Behavior, 10(4), 545-551.

Lee, S. J., \& Chae, Y. G. (2007). Children's Internet use in a family context: influence on family relationships and parental mediation. CyberPsychology \& Behavior, 10(5), 640-644.

Liu, C. Y., \& Kuo, F. Y. (2007). A study of Internet addiction through the lens of the interpersonal theory. CyberPsychology \& Behavior, 10(6), 799-804.

Luthar, S. S., \& Goldstein, A. S. (2008). Substance use and related behaviors among suburban late adolescents: the importance of perceived parent containment. Developmental Psychopathology, 20(2), 591-614.

Marsh, H. W., Balla, J. R., \& McDonald, R. P. (1988). Goodness-of-fit indexes in confirmatory factor analysis: the effect of sample size. Psychological Bulletin, 103(3), 391-410.

Meerkerk, G. J. (2007). Pwned by the internet: explorative research into the causes and consequences of compulsive internet use. Rotterdam: IVO. Dissertation. http://www.ivo.nl/?id=557.

Meerkerk, G. J., Van den Eijnden, R. J. J. M., Vermulst, A. A., \& Garretsen, H. (2009). The compulsive internet use scale (CIUS), Some psychometric properties. CyberPsychology \& Behavior, 12 (1), 1-6.

Mitchell, P. (2000). Internet addiction: genuine diagnosis or not? Lancet, 355(9204), 632.

Muthén, L. K., \& Muthén, B. O. (1998). Mplus user's guide (4th ed.). Los Angeles: Muthén \& Muthén.

Nichols, L. A., \& Nicki, R. (2004). Development of a psychometrically sound internet addiction scale: a preliminary step. Psychology of Addictive Behaviors, 18(4), 381-384.

Orford, J. (2001). Addiction as excessive appetite. Addiction, 96(1), $15-31$.

Otten, R., Engels, R. C. M. E., \& Van den Eijnden, R. J. M. M. (2007a). The relative contributions of parenting practices in smoking behavior of adolescents with and without asthma. Nicotine Tobacco Research, 9(1), 109-118.

Otten, R., Harakeh, Z., Vermulst, A. A., Van den Eijnden, R. J. J. M., \& Engels, R. C. M. E. (2007b). Frequency and quality of parental communication as antecedents of adolescent smoking cognitions 
and smoking onset. Psychology of Addictive Behaviors, 21(1), 112.

Scholte, R. H. J., Van Lieshout, C. F. M., \& Van Aken, M. A. G. (2003). Perceived relational support in adolescents. Dimensions, configurations, and adolescent adjustment. Journal of Research on Adolescence, 11(1), 71-94.

Shapira, N. A., Lessig, M. C., Goldsmith, T. D., Szabo, S. T., Lazoritz, M., Gold, M. S., et al. (2003). Problematic internet use: proposed classification and diagnostic criteria. Depression and Anxiety, 17 (4), 207-216.

Sothern, M. S. (2004). Obesity prevention in children: physical activity and nutrition. Nutrition, 20(7-8), 704-708.

Spijkerman, R., Van den Eijnden, R. J. J. M., \& Huiberts, A. (2008). Social economical differences in alcohol-specific parenting practices and adolescents' drinking patterns. European Addiction Research, 14(1), 26-37.

Subrahmanyam, K., Kraut, R. E., Greenfield, P. M., \& Gross, E. F. (2000). The impact of home computer use on children's activities and development. Future Child, 10(2), 123-144.

Van den Eijnden, R. J. J. M., Meerkerk, G. J., Vermulst, A. A., Spijkerman, R., \& Engels, R. C. M. E. (2008). Online communication, compulsive Internet use, and psychosocial well-being among adolescents: a longitudinal study. Developmental Psychology, 44 (3), 655-665.

Van den Eijnden, R. J. J. M., Vet, R., Vermulst, A., \& Van de Mheen, D. (2009). The impact of alcohol-specific parenting practices on adolescents' alcohol use and alcohol-related problems. Submitted.

Van der Vorst, H., Engels, R. C. M. E., Meeus, W., Dekovic, M., \& Van Leeuwe, J. (2005). The role of alcohol-specific socialization in adolescents' drinking behaviour. Addiction, 100(10), 1464 1476.

Van der Vorst, H., Engels, R. C. M. E., Meeus, W., \& Dekovic, M. (2006). Parental attachment, parental control, and early develop- ment of alcohol use: a longitudinal study. Psychology of Addictive Behaviors, 20(2), 107-116.

Van Rooij, A. J., \& Van den Eijnden, R. J. J. M. (2007). Monitor Internet en Jongeren 2006 en 2007. Ontwikkelingen in internetgebruik en de rol van opvoeding [Internet and Youth 2006 and 2007: Developments in internet use and the role of parenting]. IVO Reeks No. 45, Rotterdam: IVO.

Van Zundert, R. M. P., Van der Vorst, H., Vermulst, A. A., \& Engels, R. C. M. E. (2006). Pathways to alcohol use among Dutch students in regular and education for adolescents with behavioral problems: the role of parental alcohol use, general parenting practices, and alcohol-specific parenting practices. Journal of Family Psychology, 20(3), 456-467.

Vierhaus, M., \& Lohaus, A. (2008). Children and parents as informants of emotional and behavioural problems predicting female and male adolescent risk behaviour: A longitudinal crossinformant study. Journal of Youth \& Adolescence, 37(2), 211224.

Wang, R., Bianchi, S. M., \& Raley, S. B. (2005). Teenagers' Internet use and family rules: a research note. Journal of Marriage and Family, 67(5), 1249-1258.

Yen, J. Y., Yen, C. F., Chen, C. C., Chen, S. H., \& Ko, C. H. (2007). Family factors of internet addiction and substance use experience in Taiwanese adolescents. CyberPsychology \& Behavior, 10(3), $323-329$.

Young, K. S. (1998). Internet addiction: the emergence of a new clinical disorder. CyberPsychology and Behavior, 1(3), 237-244.

Young, K. S. (2004). Internet addiction: a new clinical phenomenon and its consequences. American Behavioral Scientist, 48(4), 402415.

Young, K. S., Pistner, M., O’Mara, J., \& Buchanan, J. (1999). Cyber disorders: the mental health concern for the new millennium. CyberPsychology \& Behavior, 2(5), 475-479. 